\title{
Función de la crítica inmediata
}

\section{The role of journalistic criticism}

\author{
Josep Maria Nadal Suau \\ Universidad de Baleares, España \\ jmnadalsuau@gmail.com
}

Resumen: El presente artículo reflexiona sobre la crítica inmediata y generalista, aquella de los suplementos culturales de periódicos, con el afán de desvelar algunos de los distintos límites, funciones y deberes del crítico literario, entre otros, el lugar desde dónde se escribe, la identificación del público o su función periodística. Para ello se hace hincapié en una serie de condicionantes que gravitan sobre el crítico, en especial, el sentido y posibilidades de su propia crítica enmarcada ésta en una crisis crónica financiera y de modelo de la prensa escrita. La asunción de riesgo intelectual y la aceptación de una responsabilidad primordial por parte del crítico pasa por redefinir el panorama de lo contemporáneo.

Palabras clave: crítica literaria, teoría, prensa, panorama contemporáneo, responsabilidad.

Abstract: This paper reflects on immediate and general criticism of newspaper supplements, with the aim of revealing some of the different limits, functions and duties of the literary critic, among others, the place from which it is written, the identification of the public or its journalistic function. To do this, emphasis is placed on a series of conditioning factors that weigh on the critic, especially the meaning and possibilities of his own criticism, framed in a chronic financial crisis and a model for 
the written press. The assumption of intellectual risk and the acceptance of a primary responsibility by the critic goes through redefining the panorama of the contemporary.

Keywords: Literary criticism, Literary theory, Press, Contemporary panorama, responsibility.

Recibido: 30 de marzo de 2020

Aceptado: 18 de abril de 2020 https://dx.doi.org/10.15174/rv.vi26.541

$G_{\text {para explicar una de las tareas de la crítica literaria: "Cuan- }}^{\text {eorge Steine aludía an viejo y controverido maestro }}$ do echan mano de los 'instrumentos especulativos', el crítico, el editor, el actor y el lector pisan un terreno común. El lenguaje escrito ve extender su vida gracias a esas exigencias afines, aunque acentuadas de diverso modo. O para decirlo con la frase de Ezra Pound, les toca a ellos velar porque la literatura sea noticia y siga siendo noticia" (Steiner, 1980: 43). Es fácil imaginar que tanto Steiner como Pound estaban pensando en una idea histórica de la literatura y de los oficios citados, y que el objeto de sus respectivos análisis eran los textos clásicos que regresan al tiempo presente. No será este el tema de las siguientes líneas, consagradas en cambio a la reflexión en torno a la crítica que "se aplica sobre un cuerpo presente" (Torné, 2014: 17), y que además lo hace en medios o soportes igualmente presentes, por no decir obsolescentes: esa "crítica inmediata", en fin (Estévez, 2017: 11), que piensa "la estética de la inminencia" (García Canclini apud. Speranza, 2012: 18) e intenta resaltar el carácter noticioso de la literatura estrictamente coetánea en los medios de comunicación. Pese a ello, la cita de Steiner se revela del todo pertinente para encabezar este artículo, que se moverá en un terreno acotado, el que se refiere a las condi- 
ciones bajo las que se practica este tipo de crítica hoy, en España, en los espacios periodísticos que siguen permitiendo su existencia en términos profesionales.

El debate en torno a la crítica literaria, su sentido y sus posibilidades, propicia debates intelectuales muy sofisticados, pero la realidad funciona del siguiente modo: plazos urgentes; espacios y extensiones muy ajustados; tarifas que no permiten una dedicación exclusiva, eso en los pocos casos en los que se cobra algún tipo de emolumento. Esas condiciones se enmarcan en una crisis crónica financiera y de modelo de la prensa escrita, y en la existencia de un tejido de lectores a la defensiva después de un largo proceso de merecido desprestigio de la cultura oficial. Los factores intervinientes en esa devaluación frente al público son varios, pero pueden resumirse en la conciencia generalizada de una serie de condicionantes que gravitan sobre el crítico, resumidos en estas palabras que Constantino Bértolo escribía en 2008, al filo del inicio de la crisis financiera y política que definió la larga década posterior:

En la práctica real de nuestra cotidianidad al crítico solo le puede pedir responsabilidades el director de su medio de publicación, y el crítico normalmente solo se siente vigilado por el mundillo literario: sus colegas, los escritores, los editores, los redactores jefes. La desaparición como parámetro operativo, y no solo retórico, del concepto de bien común en nuestras sociedades, y su sustitución por un mero conglomerado de intereses privados impide, desde mi punto de vista, una lectura crítica en el pleno sentido de la palabra, pero aun así ese impulso hacia lo común subsiste en la tarea del crítico, en su valor de uso, aunque luego la práctica concreta, la redacción de sus críticas, se vea alterada por otras realidades no por menos constituyentes menos activas: su propia necesidad de ocupar un lugar en el mercado literario y la obligación, por tanto, de producir mercancías, críticas, con valor de cambio para sobre- 
vivir en el duro juego de la oferta y demanda culturales (Bértolo, 2008: 99).

Limitaciones éstas, las que señala Bértolo y las insinuadas previamente, innegables, pero que además se han convertido en moneda común entre la opinión pública, cuya actitud de sospecha permanente hacia la cultura oficial ha encontrado en el estallido de las redes sociales un contrapeso nada desdeńable a los viejos mandarinatos. Limitaciones, en fin, que tienen poco que ver con las peculiaridades del trabajo académico, las hechuras del ensayo de largo aliento o las expectativas entusiastas. De todos modos, conviene negar el carácter particular de tales dificultades, que se encuentran referidas en otros muchos momentos históricos y en numerosos ecosistemas nacionales distintos.

Así, veamos dos ejemplos extraídos de la realidad mexicana contemporánea. Uno: en La feria del progreso, publicado hace casi cuatro décadas, Gabriel Zaid se burlaba de todos los imposibles que exigimos al crítico perfecto (una imposibilidad determinada por el mismo contexto que le exige mostrar en sus textos le exige mostrar en sus textos cordialidad, generosidad, entrega, integridad), y responde desde la ironía con otro imposible:

Lo ideal, por lo tanto, sería un huerfanito, sin compromisos de ningún tipo, con un talento de lector prodigio y una inteligencia crítica excepcional, que habiendo iniciado una brillante carrera literaria, recibiese de pronto una herencia fabulosa y sin ataduras de un tío abuelo desconocido y que en ese momento renunciase a escribir su propia obra para ocuparse de estimular a los demás. Los jóvenes necesitan estímulo porque están empezando. Los consagrados porque nadie atiende su obra. Los mediocres porque... pobrecitos, ¿no? (Zaid, 1982, p. 127). 
Dos: en 2018, entrevistada por la periodista Mariana H., Jazmina Barrera resume así el panorama mediático de su país:

Los periódicos están lentamente desapareciendo, las revistas también desaparecen, una por semana, es decir, quedan muy pocos espacios para difundir estas cosas, y también abundan los medios que copian tal cual la noticia de Notimex y se vuelve un teléfono descompuesto terrible. Creo que hay muchos entrevistadores que no leen los libros para los que están entrevistando y hacen preguntas aburridísimas (H., 2018: 182).

Más lejos todavía, el panorama literario alemán hacia 1970 era comentado en los siguientes términos por una autoridad indiscutible:

Pero allí donde proliferan, impertérritos, los benévolos encomiastas de la literatura contemporánea de turno y lo que quiera que los mueva... sus panegíricos no hacen más que minar la confianza en la crítica. [...] Donde se publican y reseñan libros, no pueden excluirse los favores y los gestos de amistad (y, naturalmente, también los ajustes de cuentas) (Reich-Ranicki, 2014: 63).

En realidad, la mayoría de estas cuestiones son inherentes a la existencia de la crítica moderna y a la pregunta de fondo, que es la de su función; además, requieren de un trasfondo histórico que aquí recogemos muy brevemente. Terry Eagleton sitúa su nacimiento en el contexto de la lucha burguesa contra el estado absolutista, entre el siglo XVII y el XVIII, cuando la crítica "pasa a formar parte del intercambio público de opiniones" (Eagleton, 1999: 12). Esto no significa que debamos entenderla como un factor sistemáticamente emancipador o subversivo: de hecho, el discurso crítico es portador de ideología, pero ésta puede ser conservadora, afín al 
programa homogeneizador de una determinada clase social o punitiva con la disidencia cultural. La clave que nos brinda Eagleton es esencial:

Lo que está en juego en la esfera pública, de acuerdo con su propia autoimagen ideológica, no es el poder sino la razón. La verdad, no la autoridad, es su fundamento, y la racionalidad, no la dominación, su moneda diaria. Es en esta radical disociación de la política y el conocimiento en lo que se basa su discurso; y es cuando esta disociación se torna menos plausible cuando empieza a desmoronarse la esfera pública (Eagleton, 1999: 20).

Mientras la crítica es una voz en camaradería con otras muchas que contribuyen a construir el espacio común, su función es una; en cuanto se especialice y pase del intento de forzar consensos a la voluntad de conquistar un público o un mercado, será otra. En ese momento, que Eagleton identifica con el siglo XIX, al crítico le corresponderá ser correa de transmisión de una ideología, o bien librarse al giro trascendental e idealista, a la postura del sabio inmune a lo mundano: "La única alternativa al interés desenfrenado es, parece ser, el desinterés espúreo" (Eagleton, 1999: 47). Es difícil defender la necesidad de la crítica bajo esos parámetros y, de hecho, Eagleton llega a afirmar provocativamente que, cuando el crítico ya no pueda "suturar" por más tiempo la contradicción entre las leyes del mercado y la finalidad de consensuar un modelo cultural, "habrá llegado el momento de que desaparezca de la faz de la tierra: el hombre de letras del siglo xx es más claramente una figura minoritaria que su predecesor victoriano" (Eagleton, 1999: 59). Minoritaria y, como ya hemos dicho, bajo sospecha permanente de albergar intereses, agenda propia y un plan de ruta menos relacionado con una idea de literatura que con su propia capacidad de ejercer el poder en el ecosistema literario. Y es significativa la 
conclusión a la que llega el pensador en su intento de restituir una utilidad y sentido al oficio en cuestión:

La del crítico contemporáneo es, pues, una función tradicional. [...] Una empresa de este tipo podría contribuir de manera modesta a nuestra propia supervivencia, pues queda por completo de manifiesto que sin un entendimiento más profundo de estos procesos simbólicos, a través de los cuales se despliega, se refuerza, resiste y a veces se subvierte el poder político, seremos incapaces de desenmascarar las luchas por el poder más letales a las que ahora nos enfrentamos. La crítica moderna nació de una lucha contra el Estado absolutista; a menos que su futuro se defina ahora como una lucha contra el Estado burgués, pudiera no tener el más mínimo futuro (Eagleton, 1999: 139-140).

Convengamos en que esas últimas palabras, escritas en los años ochenta, merecen una revisión en fondo y forma a la vista del panorama político actual (donde lo estatal está en tensión con lo global y lo burgués con su superación neoliberal; la lucha por el poder y su constitución no permanecen congeladas en el tiempo); sin embargo, la idea de recuperar la función primigenia de la crítica para dotarla de una relevancia mayor es lúcida, si entendemos que esa visión tradicional de la crítica se refiere a los siguientes conceptos rectores, entre otros: humildad, voluntad de participar del debate público general, superación de la especialización (aunque ésta pueda servir como piedra de toque), camaradería más que mandarinato, impugnación de la lógica del poder. Todo ello puede vertebrar un discurso académico, sin duda, pero resulta particularmente oportuno y urgente cuando hablamos de la crítica inmediata, para la cual, en primer lugar, convendría exigir la aceptación de una evidencia: su carácter periodístico. 


\section{La crítica como periodismo, y sus crisis}

Cuando el crítico escribe en un diario, un magazine o un suplemento cultural, la labor que está llevando a cabo es fundamentalmente periodística, y además se dirige a un público amplio, difícil de identificar. Esta obviedad no siempre le pareció tal a una de las voces más significativas de la crítica española contemporánea, Ignacio Echevarría, cuya tarea ha sido esencial a lo largo de las dos últimas décadas para tender puentes entre las distintas escenas latinoamericanas y la española, esta última más cerca del aislamiento que de la centralidad. En un artículo muy útil al respecto del tema que nos ocupa, Echevarría confiesa haber negado durante mucho tiempo la adscripción del crítico al catálogo de las formas periodísticas, amparado siempre en la naturaleza híbrida del género, y a continuación admite que sus propias convicciones sobre este asunto han cambiado, lo cual tiene consecuencias inmediatas sobre el desempeńo del crítico, puesto que "está condenado a seguir transformándose en la medida en que el periodismo lo haga, tratando no solo de mantener un lugar propio en el marco que éste le brinda, sino de reconquistar el papel bastante más preponderante que en otros tiempos llegó a desempeñar dentro del mismo" (Echevarría, 2017: 160). Así que, en un abanico que sitúa sus intervenciones entre las mil doscientas y las quinientas palabras, el crítico de suplemento cultural tiene que ofrecer la suficiente cantidad de información (es decir, contrastada y diferenciada de la que ya ofrecen las editoriales) sobre el autor, la obra y su situación en la literatura contemporánea. De hecho, si se siente con fuerzas, tal vez merezca la pena que informe sobre esa misma contemporaneidad, cuyo conocimiento por parte del lector no puede darse por sentado. Además, ese mismo lector le va a exigir que emita un juicio claro sobre la obra, un requisito cuyas motivaciones son muy comprensibles pero que, al mismo tiempo, puede contribuir 
a olvidar que lo más importante o estimulante de ese trabajo reside en el mero proceso de enfrentar el libro, cargarlo de ideas, sugerirle correspondencias... En definitiva: leer. Así que el crítico, en un espacio que empieza a resultar casi telegráfico, también intentará introducir esas variables. Y todo eso deberá hacerlo con algo que merezca calificarse, en alguna medida, de estilo propio, puesto que "la crítica literaria es una estética en acto" (Berardinelli, 2016: 31), teniendo en cuenta que estará sometido a necesidades diversas y casi contradictorias, ya que debe ser personal pero no desbordante, sofisticado y claro, denso y ligero. En definitiva, "capacidad de síntesis" es un concepto que se queda pequeńo para los equilibrios que está obligado a hacer un crítico en la España de los suplementos jibarizados, en el mejor de los casos, o inexistentes, en los peores, un panorama que se resume así:

Se están produciendo una serie de transformaciones, probablemente debidas, no solo a las formas de periodismo, sino a los intereses de los medios de comunicación, al público y a las condiciones materiales de lectura de los suplementos. Es significativo que, de los periódicos nacidos en el entorno digital, como InfoLibre, eldiario.es, El Confidencial, El Español, etc., solo InfoLibre pueda presumir de tener una revista de libros, Los diablos azules. Los demás ofrecen una sección de cultura bastante heterogénea en la que no se publican reseñas de libros con regularidad -en muchos casos, ni siquiera se publican-, sino noticias a propósito de autores, publicaciones, estrenos de películas, e incluso los últimos casos de denuncias a personalidades del cine americano (González Gómez, 2018: 23).

Es cierto que cabría añadir otros ejemplos más esperanzadores: así, el digital español Contexto no acoge propiamente reseñas, pero sí textos críticos, e incluso dispone de una sección titulada 'El 
ministerio', coordinada por Ignacio Echevarría y Gonzalo Torné, que estimula el debate literario y la experimentación con formas nuevas de discurso crítico; en Argentina, el digital Otra parte se ha convertido desde hace un lustro en una referencia insoslayable; otra vez en España, el escritor Vicente Luis Mora logró hace ya más de una década convertirse en una voz destacada de la crítica en lengua castellana solo desde su blog Diario de lecturas, sin necesidad de colaborar en medios convencionales salvo puntualmente. En todo caso, en el momento de cerrar este artículo, los más de dos meses de estado de alarma decretados por la pandemia de la Covid-19 y la abrupta crisis económica consecuente no hacen sino oscurecer el panorama descrito de un modo todavía imposible de cuantificar.

A todo ello se le añade la diversificación de voces y espacios que ha propiciado Internet: blogs, notas en la plataforma Goodreads, muros en las redes sociales... Con Eagleton en mente, podemos plantear la sospecha de que esta enorme heterogeneidad, promocionada como ampliación casi infinita de la esfera pública, es más bien la avanzadilla sofisticada de la lógica precaria, comercial y disgregadora. Remedios Zafra lo explica así en su ensayo El entusiasmo:

En el debate cotidiano y rápido online no es fácil la dialéctica argumentada, el acceso a opiniones distintas, al disentimiento razonado. Cuando la mayoría de los participantes de una red son "afines" que retroalimentan una causa, bajo la apariencia de diversidad predomina "un único punto de vista" y a menudo falta imaginación y palabra menos vanidosa, más responsable. Ni la inercia promovida por la máquina ni la de una red ayudan a generar duda y a cuestionar, tampoco a pedir tiempo para pensar mejor las cosas. Pero sobre todo parece no estar favoreciendo la diversidad de voces que coexistan sin violencia o sin rechazo. El tiempo ha sido 
sustituido por un botón que apaga para excluir o bloquear al que disiente y la velocidad anima al exabrupto.

La cosa parece encajar bien en el tipo de mercado que contribuye a "reforzar lo que nos gusta", la convivencia con "aquellos que nos caen bien" y lo que ya hemos elegido antes (sobre lo que dejamos pistas en nuestras huellas online y que la máquina retroalimenta). [...] La lógica es claramente excedentaria y exponencial (Zafra, 2017: 229-230).

Frente a todo ello, el crítico generalista tiene, todavía, la responsabilidad primordial de ser útil al lector. Sin paternalismos, porque, de hecho, él mismo es en esencia un lector. Un paso en falso en dirección a la soberbia, y el receptor descartará la validez del texto. Un movimiento deshonesto o interesado, y no lo escuchará más. Si evita estos dos errores, el crítico tendrá la oportunidad de establecer una relación fértil con otros iguales y construir poco a poco algo que perfectamente puede calificarse de tejido cívico. Echevarría lo explica al revés, si bien el resultado es idéntico: "El crítico se dirige al lector en cuanto crítico él mismo, en cuanto lector imbuido de una cierta inquietud y de unos ciertos rudimentos 'artísticos', vamos a decirlo así, que autorizan a dirigirse a él dando por supuestas según qué cosas, empleando cierto nivel -por mínimo que sea- de complicidad" (Echevarría, 2018: 176). En segundo lugar, un crítico puede serle útil a un libro, a una obra necesitada de alguien que la entienda, la sitúe y la haga llegar a las manos de sus receptores adecuados. Y solo en última instancia, el buen crítico es útil al escritor, al que descifra y al que a veces se adelanta. Probablemente no se escribe para un 'público', pero menos todavía para nadie: la recepción sigue siendo necesaria para que la literatura sea tal cosa. El crítico (esto es, la crítica profesional y publicada en papel) ya no desequilibra ni capitaliza esa recepción, pero prolonga una cadena que en ocasiones, sin él, se habría roto. 
Cuando trabaja en medios más o menos generalistas, esa cadena lo vincula a lectores de todo tipo, especialistas o no, eruditos o no, cercanos o no. Es imposible saber quiénes son. Sin embargo, es absurdo ejercer ese oficio sin tenerlos en cuenta, sin aspirar a serles de utilidad. No nos referimos a hacer un planteamiento didáctico de la escritura, sino a mostrar una voluntad de comunicación y precisión que sea compatible con asumir riesgos intelectuales.

\section{La autoridad de Sísifo:}

\section{la crítica como una conversación revisable}

Lo más urgente que le corresponde hacer al crítico generalista es redefinir el panorama de lo contemporáneo (cartografiarlo, si queremos servirnos de una analogía al borde del cliché), "complejizando las redes de conexiones con relaciones flexibles que preservan la autonomía relativa de la esfera propia, y aumentan al mismo tiempo la tensión y la variedad de los enlaces"' (Speranza, 2012: 13). Así, por un lado, el crítico

mira y lee obras, artistas y autores porque cree que el primer impulso de la crítica sigue siendo descifrar cómo una obra, un artista o un autor dice o hace algo que no había dicho o hecho ningún otro. Ni la teoría del texto, ni los estudios culturales, ni la posautonomía nos han podido convencer de que ya no hay artistas ni

\footnotetext{
${ }^{1}$ Speranza se refiere aquí a la tarea de críticos y artistas por igual, con especial atención a la relación de la escena internacional con la creación latinoamericana (una categoría, esta última, que para ella no existe, pero sin embargo se ve obligada a utilizar mientras sea el mercado quien defina esa relación). Es relevante que Speranza sea la directora, junto a Marcelo Cohen, de uno de los espacios de crítica no académica más importantes de la última década en lengua castellana, la revista digital Otra parte.
} 
autores, ni devaluar esa invitación de la crítica a pensar con el arte y conversar con las obras (Speranza, 2012: 17).

Pero esta aspiración, tan noble y aséptica en su postulado primigenio, no es tan fácil de cumplir cuando el crítico sigue de cerca la trayectoria de sus compañeros de generación (lo cual, en gran medida, es el trabajo más natural y visible de cuantos le corresponden), porque entran en juego algunos elementos de simpatía o solidaridad inconscientes, y puede que en algún caso incluso necesarios: en el dibujo de la propia generación, el crítico es de algún modo parte del territorio a cartografiar, hay un problema de perspectiva que no es tanto ético como intelectual. El conflicto puede llevarse más lejos: del éxito oficial o mercadotécnico de un autor generacional y estéticamente afín, nacen oportunidades oficiales o mercadotécnicas para el status del crítico que lo ha descubierto, amparado, acompañado o defendido. Quizás por eso, "para un crítico es importante ser iconoclasta. Derribar los falsos ídolos libera la mente y la prepara para apreciar lo mejor" (Berardinelli, 2016: 79). Además, esa actitud también previene la convergencia espuria de intereses. A fin de cuentas, incluso en el caso de que se practique esa iconoclastia, "nuestro crítico hipotético forma parte de ese mismo sistema literario cuya decadencia ha reseñado con tanta finura. Un sistema literario fuertemente protegido, custodiado, vigilado y mimado en proporción inversa a su tamaño, pues se trata de un nicho ecológico muy eso, muy nicho, muy estrecho: todos se codean con todos, se ven todas las semanas, se llaman, se guasapean" (Fernández, 2019). Sin embargo, hay que lograr establecer la distancia adecuada y alzar el listón. O se es exigente, o se es irrelevante, al menos para contribuir al desarrollo de una escena literaria homologable a las más enérgicas.

Para que el juicio del crítico tenga valor, conviene que el lector sepa desde dónde escribe. Los de la "Autoridad" y la función del 
crítico son en realidad dos conceptos que podemos entender de varias maneras, y que llevaban décadas siendo puestos en cuestión o revisados, ${ }^{2}$ pero el estallido de los blogs y las redes sociales ha implicado, como ya vimos un poco más arriba, la desaparición del régimen jerárquico claro que definió el sistema literario del siglo xx: hoy, la voz experta que se comunica desde los suplementos culturales ejerce una influencia mezclada con otras muchas referencias y prescripciones que pesan lo mismo que ella. Si goza de la suficiente lucidez, esto le permite ejercer funciones mucho más interesantes que la del mandarinato: mantener una conversación. $\mathrm{Y}$ en esa conversación, sus interlocutores quieren saber quién es. ¿Se puede ser buen lector sin acabar forjando una cierta idea acerca de lo que es o no es literatura? Al fondo del trabajo de un crítico hay, como ya dijimos, una estética. Puede ser más o menos inclusiva, más o menos desprejuiciada, y hasta puede permitirse guilty pleasures y heterodoxias respecto de sí misma; pero si no está mínimamente vertebrada, no le servirá de nada a nadie. Como es evidente, esta afirmación comporta todo tipo de variables conflictivas: ¿Puede convertirse en mero vehículo para la defensa de las propias ideas estéticas? Y en ese caso, ¿no estaríamos hablando de un texto que habla de uno mismo, más que de un texto consagrado al trabajo de otro? Y entonces, ¿tiene sentido el ejercicio de la crítica? Se diría que el sentido de la crítica consiste en no dejar de hacerse esas preguntas, y permitir que condicionen de forma explícita la relación del discurso crítico con el discurso literario que

${ }^{2}$ El presente artículo tiene unas pretensiones y una extensión que hacen imposible, y desaconsejable, desarrollar este punto. Con todo, y para situar al lector en el contexto español, vale la pena mencionar aquí la reciente publicación colectiva Pensamiento y crítica literaria en el siglo XX (Pozuelo Yvancos, et al., 2019), que revisa minuciosamente las ideas críticas más significativas que recorrieron el sistema plurilingüe de la cultura espańola hasta poco antes de la aparición de la web. 
se analiza. Es decir, una posición incómoda y autocrítica, necesaria incluso en un género tan menor, humilde y restringido como la reseńa periodística. No sabemos si podemos salir de nosotros mismos, pero mientras tanto conviene preguntarse sin cesar en qué consiste ese "uno mismo". El crítico, en menor o mayor medida, debe mostrar una visión propia de las exigencias y urgencias de la época. Es decir, debe estar en el mundo. No sirven los burócratas de lo literario ni los practicantes del vaciado ideológico. Alfonso Berardinelli caracteriza así al buen crítico:

Aquellos a los que llamo Críticos sienten, por último, la presunción de ser críticamente los más coherentes, ya que no creen ni creer ni saber, o más concretamente, sostienen que las certezas solo pueden ser subjetivas, transitorias y mutables: si afirman algo lo hacen con prudencia y alzan inmediatamente las manos diciendo: esto que estoy diciendo ahora, vale aquí, vale ahora y por lo que a mí respecta, decidid vosotros si por casualidad puede tener que ver, en otra parte y en el futuro, también con vosotros (Berardinelli, 2015: 22).

Por lo tanto, se da en el crítico una aceptación del carácter coyuntural y revisable de sus propias posturas, una apertura a su caducidad y sus limitaciones, y un afán de compartir ideas con el lector e incidir sobre él, pero desde una horizontalidad consciente y aceptada, más allá del escepticismo sarcástico con el que Cyril Connolly afirmaba que el suyo era un oficio "en el que los triunfos son efímeros y solo la esclavitud de la tarea es permanente, y en el que el futuro no ofrece nada seguro, excepto la certeza de acabar convertido en un gacetillero" (Connolly, 2005: 622). Esa perspectiva poco halagüeña es perfectamente plausible, y sin embargo la humildad del crítico es vocacional, no la consecuencia de un fracaso; "el crítico tiene necesidad de sentido común, de experiencias 
comunes y de un lenguaje en el que se puedan decir cosas que quizá no interesan a Dios y que desde luego no sirven al Progreso" (Berardinelli, 2015: 30).

\section{Crítica literaria y primera persona}

En relación con todo lo anterior, la crítica periodística o inmediata arrastra desde hace tiempo una discusión significativa en torno al uso del Yo en el texto. De hecho, a mediados de los años treinta el mismo Connolly explicaba ya lo siguiente:

La primera vez que me dieron novelas para reseñar me confiaron las dos reglas de oro de este género del periodismo. Nunca usar la primera persona del singular y siempre relacionar los libros por algún denominador común [...]. Parece llegada la hora de romper estas reglas. Un mero veto a un pronombre personal no impide a un crítico hablar de sí mismo, y ya que la reseńa de novelas es a tal punto un asunto de preferencias personales, parece absurdo negar este hecho (Connolly, 2005: 623-624).

Hemos citado antes a Echevarría, quien ha explicado con gran inteligencia que como reseñista nunca utilizó la primera persona, el manido en mi opinión, para sostener sus posturas: a fin de cuentas, ni él ni el autor pintaban gran cosa en una confrontación que solo concernía al libro y a la reseña. "Se trataba siempre del enfrentamiento de un artefacto retórico contra otro artefacto retórico", les dijo a Antonio Orejudo y Miguel Roig en una entrevista para El Diario (Orejudo/Roig, 2012). Es cierto, pero la primera persona es también, de hecho, un dispositivo retórico, un rasgo de estilo, y tal vez hoy sea más pertinente y convincente que nunca. En la era de las redes sociales, de la extimidad radical, y con cualquier idea de verticalidad cultural puesta en discusión, puede que en mi opinión 
sea la fórmula que haga inteligible una posición crítica a un público amplio. El término lacaniano 'extimidad' ha sido utilizado recurrentemente para caracterizar la cultura de los tres últimos lustros:

A fin de comprender este fenómeno tan contemporáneo de exhibición de la intimidad -o la extimidad-, se impone una primera pregunta: ¿estas nuevas formas de expresión y comunicación que hoy proliferan en la Web - blogs y fotologs, redes de relaciones, webcams y vídeos caseros- deben considerarse vidas u obras? Todas esas escenas de la vida privada, esa infinidad de versiones de usted y yo que agitan las pantallas interconectadas por la red mundial de computadoras, ¿muestran la vida de sus autores o son obras de arte producidas por los nuevos artistas de la era digital? ¿Es posible que sean, al mismo tiempo, vidas y obras? ¿O quizá se trata de algo completamente nuevo, que llevaría a superar la clásica distinción entre estas dos nociones? (Sibilia, 2008: 35).

La misma autora, un poco más adelante, multiplica esas preguntas:

Esa exposición abierta a los ojos del mundo entero, ¡es apenas un detalle sin mucha importancia? No parece que así sea o, por lo menos, esa exhibición pública de la intimidad no es una menudencia que merezca ser menospreciada. La interacción con los lectores, por ejemplo, se presenta como un factor fundamental en los textos de la blogosfera. Por otro lado, los márgenes de esos relatos están tachonados de links que abren ventanas a otros blogs y fotologs, haciendo de cada texto un nudo de una amplia red hipermediática (Sibilia, 2008: 69-70).

Es cierto que no son preguntas enmarcadas en la reflexión acerca de la crítica generalista, pero deben trasladarse a ella si se quie- 
re responder con garantías a las necesidades del tiempo presente. Confieso que en este asunto he dado algunos tumbos en mi propio trabajo. Cursé mis estudios universitarios en los años en que aparecía y se consolidaba el formato blog en la red, y mis primeros pasos profesionales como crítico se produjeron en 2004, de forma simultánea a la escritura de un blog propio en el que, de forma deliberada, costaba distinguir lo confesional de lo crítico (Nadal, 2010). ${ }^{3}$ En mi trabajo para El Cultural, al reseńar distintos libros, a veces desaparezco bajo la máscara de una tercera persona que presenta reminiscencias del estilo académico, otras me paseo por la reseńa como un personaje diseńado, ya lo insinué antes, con fines estilísticos. ¿Las circunstancias personales tienen cabida en el reseñismo, la historia por la que uno llegó a un libro, los estados de ánimo que condicionaron su lectura...? La respuesta canónica es que no, sobre todo si se manejan con ingenuidad $k i t s c ;{ }^{4}$ pero cabe revisar una afirmación tan contundente, no solo desde una pers-

${ }^{3}$ Parapetos es una antología de mis primeras publicaciones como crítico generalista, sin mayor interés que el coyuntural. Sin embargo, las tensiones e intercambios que se producen entre sus secciones 'Crítica literaria' (que reproduce textos publicados en prensa) y 'Emboscado' (que recoge medio año de escritura blogger) sirve como ejemplo modesto de las dificultades para sostener un discurso crítico desembarazado de cualquier componente formal confesional para un miembro de mi generación. Por lo demás, allí se lee una afirmación, sin duda tautológica, pero que gravita sobre mi propio trabajo y sobre el planteamiento general de este artículo: "Pensamiento crítico significa pensamiento autocrítico" (Nadal, 2010: 198)

${ }^{4}$ Hace unos años, la entrada titulada 'La crítica kitsch (o el retorno de la crítica conservadora)", en el blog del pensador Alberto Santamaría, provocó un tan estimulante como desabrido debate acerca de las formas que el comentario literario estaba adoptando en la web: un tipo de crítica que se caracterizaría, a juicio de Santamaría, por una preocupación más orientada al efecto inmediato y lúdico que provoca que al argumento, y que tiene su principal rasgo estilístico en una primera persona provocadora y "sincera". El debate quedó superado hace tiempo, y sus participantes ocupan hoy lugares y discursos distintos a los de 
pectiva contemporánea sino, también, aludiendo a un provocador genial como Oscar Wilde, quien sostenía que la crítica "es la única forma civilizada de autobiografía, porque no se ocupa de los acontecimientos, sino de los pensamientos de la vida de un ser; no de las contingencias de la vida física, sino de las pasiones imaginativas y de los estados superiores de la inteligencia" (Wilde, 2017: 50). La primera persona aplicada a su escritura no sería sino un pacto formal entre crítico y lector acerca de esa evidencia.

\section{Contra las fajas: la crítica como lenguaje ajeno a la publicidad}

Otra cosa más sobre el estilo. He aquí la mayor exigencia que se le puede plantear a un crítico: su escritura nunca debe confundirse con publicidad. Por decirlo de un modo gráfico y un tanto provocador, que una editorial decida escoger una frase de su reseńa para reproducirla en faja y vender una novela no necesariamente debería resultarle la mejor noticia posible (pese a que el crítico se alegra cuando ocurre, puesto que la industria le reconoce así una existencia más o menos relevante). Una crítica positiva sigue siendo una crítica, es decir, un texto más concebido para analizar que para celebrar, aunque quepa hacer las dos cosas. La concesión a la información es imprescindible cuando se escribe en un medio, pero la publicidad es otra cosa. Ni un juicio favorable ha de ser mera publicidad del libro (sí una invitación a su lectura, que no es lo mismo), ni una crítica negativa puede ser una excusa para que el crítico se publicite a sí mismo. La dureza también tiene que ser limpia, racional. De todos modos, aquí es muy oportuno citar a Jürgen Habermas, cuya Historia y critica de la opinión pública se

entonces, pero cabe señalarlo como un punto significativo al respecto de ese Yo que comentamos aquí (Santamaría, 2012). 
encuentra en la base de las ideas de Terry Eagleton citadas previamente, para esquivar un margen de confusión terminológico inevitable: en efecto, Habermas nos recuerda que "el uso lingüístico de 'público' y 'publicidad' denota una variedad de significaciones concurrentes. Proceden de fases históricas diversas y, en su sincrónica aplicación a las circunstancias de la sociedad burguesa industrialmente avanzada y social-estatalmente constituida, se prestan a una turbia conexión" (Habermas, 2018: 41). Si hablamos del crítico como de un lenguaje público, esto es, accesible a todos, describimos con exactitud un objetivo legítimo; con "publicitario" nos referimos en cambio a lo que es sinónimo de marketing, esto es, un lenguaje seductor, accesible a todos en una primera aproximación, pero diseńado para revertir en un beneficio estrictamente privado.

En todo caso, retomando esa necesidad de esquivar lo publicitario en la prosa, ańadamos que eso implica una minuciosa cadena de decisiones. Si Martin Amis convocaba al escritor a una lucha contra el cliché (Amis, 2003), el crítico trabaja en un sentido parecido. Los clichés y los automatismos del lenguaje se reproducen con enorme facilidad. Un ejemplo: en El autor y la escritura, Ernst Jünger establece que "también interesar es una palabra moderna: tal o cual pensador ya no interesa. Una palabra comercial que, como incuestionado, tiene valor peyorativo. Aquí hay que examinar: ¿quién es el que ya no interesa y a quién?” (Jünger, 1987: 134). Así, decir de algo que es interesante no es solo una vaguedad, sino un préstamo de la lógica mercantil, y por lo tanto un crítico (al menos, el crítico que escribe este artículo) probablemente deba optar por descartar esa expresión en la mayor parte de contextos. Con todo, Echevarría recomienda al crítico "asumir, hasta cierto punto, su propia condición de publicista” (Echevarría, 2017: 161), en tanto que está elaborando "un artefacto ideológico" (Echevarría, 2017: 163) que aspira a operar de modo eficaz sobre la realidad. Sofía González Gómez razona de un modo parecido al señalar 
que los críticos españoles más jóvenes tienden a priorizar las sensaciones subjetivas a los discursos teóricos; explica ese fenómeno nuevo del siguiente modo: "La ya célebre cita de Joseph Ledoux 'la emoción es más potente que la razón' y la tesis de su libro El cerebro emocional se han demostrado ciertas, y de ese poder de llegar a las personas se han visto influidos textos como las reseñas" (González Gómez, 2018: 23). Ciertas o no, ambas afirmaciones inciden en la muy relevante relación que la crítica periodística mantiene con su contexto sociocultural y su preocupación por su propia recepción (la recepción de la recepción, podríamos decir) entre un público que, al ser no especializado, obliga a equilibrios muy distintos a los canónicos. Lo resumía muy bien Mark Fisher al apostar por un tipo de discurso "intelectual sin ser académico, popular sin ser populista” (Fisher, 2019: 146).

Finalmente, otra responsabilidad del crítico, una de las más estimulantes, es la de registrar el presente de la literatura para entender el presente sin más. Cuando leemos, reseñamos o pensamos a nuestros contemporáneos, el gran estímulo intelectual deja de ser el de afrontar libros canónicos, títulos "imprescindibles” u obras maestras (nadie sabe cuándo o cómo se producen ese último tipo de apariciones tangibles, si es que lo hacen) y pasa a ser el de abarcar una red compleja, y aparentemente muy dispersa, de manifestaciones estéticas, ideológicas, autorales o estructurales. El mundo y la literatura siguen pareciéndose, a condición de que haya una mirada capaz de descubrir en qué. Ahí entra en juego el crítico, que sigue siendo decisivo. 


\section{Bibliografía}

Amis, Martin, 2003, La guerra contra el cliché, Ángel Gurria Quintana (trad.), Anagrama, Barcelona.

Berardinelli, Alfonso, 2015, El intelectual es un misántropo, Salvador Cobo (ed., trad.), Ediciones El Salmón, Madrid.

, 2016, Leer es un riesgo, Salvador Cobo(ed., trad.), Círculo de Tiza, Madrid.

Connolly, Cyril, 2005, Obra selecta, Miguel Aguilar, Mauricio Bach y Jordi Fibla (trad.), Lumen, Barcelona.

Eagleton, Terry, 1999, La función de la crítica, Fernando Inglés Bonilla (trad.), Paidós, Barcelona.

Echevarría, Ignacio, 2017, "El crítico como periodista", en Cada mesa, un Vietnam, Enric González (ed.), Jot Down Books, Madrid, pp. 159-182.

Estévez, Francisco, 2017, Con la novela a cuestas, El Viajero inmóvil, México.

Fernández, Xandru, 2019, "Cómo aprendí a amar la crítica literaria”, ctxt.es, Madrid. Disponible en: https://ctxt.es/ es/20190403/Culturas/25415/critica-literaria-editoriales-internet-turbocapitalismo-xandru-fernandez.htm (Consultado: 8/III/2020).

Fisher, Mark, 2019, K-Punk, volumen 1, Fernando Bruno (trad.), Caja Negra, Buenos Aires.

González Gómez, Sofía, 2018, “Tendencias de la crítica literaria en prensa. Sobre el desplazamiento generacional en los suplementos literarios", Ínsula, núm. 862, Barcelona, octubre, pp. 18-23.

H., Mariana, 2018, Neurosis, sustancias y literatura, Reservoir Books, México. 
Habermas, Jünger, 2018, Historia y crítica de la opinión pública, Antonio Doménech (versión de), Gustavo Gili, Barcelona.

Nadal Suau, Josep Maria, 2010, Parapetos, Lleonard Muntaner Editor, Palma.

Orejudo, Antonio; Roig, Miguel, 2012, "Una mala crítica es un ajuste de cuentas legítimo. Entrevista a Ignacio Echevarría”, Eldiario.es, Madrid. Disponible en: https://www.eldiario.es/ Kafka/burbuja_literaria/Ignacio-Echevarria_0_79092193. html (Consultado: 09/III/20).

Pozuelo Ycancos, José María, et al., 2019, Pensamiento y crítica literaria en el siglo XX, Cátedra, Madrid.

Reich-Ranicki, Marcel, 2014, Sobre la crítica literaria, Juan de Sola (trad.), Elba, Barcelona.

Santamaría, Alberto, 2012, "La crítica kitsch (o el retorno de la crítica conservadora)". Disponible en: http://albertosantamaria.blogspot.com/2012/02/la-critica-kitsch-o-el-retorno-de-la. html (Consultado: 12/III/20).

Sibilia, Paula, 2008, La intimidad como espectáculo, Fondo de Cultura Económica, Buenos Aires.

Speranza, Graciela, 2012, Atlas portátil de América Latina, Anagrama, Barcelona.

Steiner, George, 1980, Después de Babel, traducción de Adolfo Castañón, Fondo de Cultura Económica, México, 578 pp.

Torné, Gonzalo, 2014, "Un talento crítico disparado en todas direcciones", en Kermode, Frank, El leve ruido del piso de arriba, Ediciones Universidad Diego Portales, Santiago de Chile, pp. 9-17.

Wilde, Oscar, 2017, El crítico como artista y otros ensayos, Daniel Céspedes (sel., y pról.), La Habana.

Zafra, Remedios, 2017, El entusiasmo, Anagrama, Barcelona.

Zaid, Gabriel, 1982, La feria del progreso, Taurus, Madrid. 